\title{
Zeylenone represses the progress of human prostate cancer by downregulating the Wnt/ $\beta$-catenin pathway
}

\author{
SHAOHUA ZENG ${ }^{1 *}$, BAOYI ZHU ${ }^{1 *}$, JUN ZENG $^{2}$, WENQI WU ${ }^{3}$ and CHONGHE JIANG ${ }^{1}$ \\ Departments of ${ }^{1}$ Urology Surgery and ${ }^{2}$ Gastrointestinal Surgery, The Sixth Affiliated Hospital of Guangzhou \\ Medical University, Qingyuan People's Hospital, Qingyuan, Guangdong 511518; ${ }^{3}$ Department of Urology, \\ Minimally Invasive Surgery Center, The First Affiliated Hospital of Guangzhou Medical University, \\ Guangdong Key Laboratory of Urology, Guangzhou, Guangdong 510230, P.R. China
}

Received January 17, 2018; Accepted August 31, 2018

DOI: $10.3892 / \mathrm{mmr} .2018 .9564$

\begin{abstract}
Prostate cancer (PCa) is one of the most common types of cancer in the urinary system in men. Zeylenone (Zey), a naturally occurring cyclohexene oxide, has an anticancer effect. In the present study, the role and potential mechanism of Zey in PCa were examined. The proliferative, invasive and migratory capacities of DU145 cells were analyzed using Cell Counting Kit-8, transwell and wound healing assays, respectively. The expression levels of matrix metalloproteinase (MMP)-2 and MMP-9 were determined with an ELISA. Reverse transcription-quantitative polymerase chain reaction and western blotting assays were performed to evaluate the expression levels of extracellular matrix, epithelial-mesenchymal transition and $\mathrm{Wnt} / \beta$-catenin pathway-associated factors. In the present study, it was observed that Zey not only suppressed the viability of DU145 cells; however, it additionally attenuated the invasive and migratory capacities of cells in a concentration-dependent manner. Treatment of Zey decreased the expression levels of MMP-2, MMP-9 and fibronectin-1; whereas, it increased tissue inhibitor of metalloproteinases-1 and collagen-1 expression levels. Additionally, the vimentin expression level was downregulated, however, the epithelial-cadherin expression level was upregulated in cells treated with Zey. Furthermore, Zey decreased the expression levels of wnt5a, $\beta$-catenin and cyclin D1. In conclusion, the present results demonstrated that Zey decreased the viability and metastasis of human PCa cells (DU145), via
\end{abstract}

Correspondence to: Dr Chonghe Jiang, Department of Urology Surgery, The Sixth Affiliated Hospital of Guangzhou Medical University, Qingyuan People's Hospital, B24 Yinquan Road, Qingyuan, Guangdong 511518, P.R. China

E-mail: hezhongjiang168abc@163.com

*Contributed equally

Key words: Zeylenone, prostate cancer, metastasis, Wnt/ß-catenin pathway the Wnt/ $\beta$-catenin signaling pathway. Therefore, Zey may be applied as a novel drug for treating PCa in the future.

\section{Introduction}

Prostate cancer (PCa) is one of the most common types of cancer affecting male health (1). In recent years, the incidence of PCa in China has been increasing annually and the age of onset is becoming younger. This phenomenon may be accounted for by lifestyle, longevity, aging and diagnostic technology $(2,3)$. Local invasion or distant metastasis may occur once the lesion develops to the later stages (4). The survival rate of patients with localized PCa is $\sim 100 \%$, whereas, the annual survival rate of patients with distant metastasis is reduced to $29 \%$ (5). Therefore, it is necessary to identify a treatment to inhibit the growth and metastasis of PCa.

For decades, isolated products from plants served a pivotal role in the treatment of malignant tumors $(6,7)$. Zeylenone (Zey), a naturally occurring cyclohexene oxide, is isolated from Uvaria grandiflora Roxb (8). Though Zey exhibits strong toxicity to tumor cells, it is less toxic to normal cells $(8,9)$. Previous studies have demonstrated that Zey exhibits potent activity against tumors, for example, cervical carcinoma and lung cancer $(8,10)$. In cervical carcinoma, a previous study demonstrated that Zey was able to induce the apoptosis of cervical carcinoma cells (8). Another previous study on lung cancer tumor-bearing mice observed that the Zey-loaded mice demonstrated an antitumor effect (10). A previous study has reported that Zey had inhibitory effect on proliferation of PC-3 cells (11). However, the role of Zey in PCa and its underlying mechanism requires further investigations.

The extracellular matrix (ECM) and epithelial-mesenchymal transition (EMT) are closely pertinent to tumor metastasis $(12,13)$. The ECM is primarily composed of interstitial collagen, laminin, elastin and fibronectin. In the dynamic balance of metabolic renewal, degradation and remodeling, it maintains the microenvironment of tumor cell growth and regulates the gene expression of tumor cells in contact with it, thereby affecting the metabolism, growth and metastasis of tumors $(12,14)$. The occurrence of EMT is a dynamic and multi-step process, which includes the loss of intercellular adhesion, destruction of the basement membrane and ECM, 
and remodeling of cytoskeleton, ultimately resulting in enhanced motility and migration of tumors (15).

The Wnt $/ \beta$-catenin signaling pathway is highly conserved in biological evolution and its members are highly homologous from Drosophila melanogaster to higher mammals. The pathway regulates the stability of transcription factor $\beta$-catenin and is dependent on the expression of the $\beta$-catenin gene $(16,17)$. The $W n t / \beta$-catenin signal transduction pathway is associated with human cancer. Therefore, previous studies of the pathway not only aided understanding of the mechanism of cancer; however, additionally suggested a series of novel targets for the treatment of cancer (18-20).

In the preset study, the effect of Zey on the viability and metastasis of human PCa cell line DU145 was investigated. The present study additionally aimed to examine whether potential mechanisms are regulated by the ECM, EMT and Wnt/ $\beta$-catenin pathways. The present study demonstrated the role of Zey on human PCa and its possible mechanism of action. The present study may provide a novel candidate anti-tumor agent in the treatment of $\mathrm{PCa}$.

\section{Materials and methods}

Preparation of Zey. Zey was obtained from Yuanye Bio-technology Co., Ltd. (Shanghai, China) with a purity of $98 \%$. Zey was prepared for subsequent experiments as described previously (9) and was diluted to the desired concentrations $(2.5,5,10,20$ and $40 \mu \mathrm{mol} / \mathrm{l})$.

Cell culture. The human PCa cell line DU145 (American Type Culture Collection, Manassas, VA, USA) was cultured in Eagle's Minimum Essential Medium (American Type Culture Collection) with $10 \%$ fetal bovine serum (FBS; American Type Culture Collection) and $1 \%$ penicillin/streptomycin (Thermo Fisher Scientific, Inc., Waltham, MA, USA) in a $37^{\circ} \mathrm{C}$ incubator (Thermo Fisher Scientific, Inc.) with $95 \%$ humidity and $5 \% \mathrm{CO}_{2}$.

Cell Counting Kit-8 (CCK-8) assay. Cells were inoculated in 96 -well plates $\left(2.5 \times 10^{3}\right.$ cells/well $)$ and cultured in an incubator for $24 \mathrm{~h}$. Subsequent to being cultured, cells were exposed to different concentrations of Zey at $0,2.5,5,10,20$ and $40 \mu \mathrm{mol} / \mathrm{l}$ for 12, 24 and 48 h. CCK-8 solution (Beyotime Institute of Biotechnology, Haimen, China) was added to the cells and the plate was transferred to the incubator for $4 \mathrm{~h}$. Finally, absorbance was measured at $450 \mathrm{~nm}$ with a FilterMax F3/F5 microplate reader (Molecular Devices, LLC, Sunnyvale, CA, USA).

Matrigel assay. Cells were inoculated in 6-well plates $\left(2.5 \times 10^{4}\right.$ cells/well) and subsequently cultured in an incubator for $24 \mathrm{~h}$. Cells were treated with different concentrations of Zey for $48 \mathrm{~h}$ at 10 (Zey1), 20 (Zey2) and 40 (Zey3) $\mu \mathrm{mol} / 1$. The untreated cells served as a control. BD matrigel (Beijing Solarbio Science \& Technology Co., Ltd., Shanghai, China) was filled in the upper chamber of the transwell plates at room temperature for $25 \mathrm{~min}$. Subsequently, the transwell membrane was placed in the culture plate. F-12K medium was added into the upper chamber for $20 \mathrm{~min}$ and subsequently removed. F-12K medium with $15 \%$ FBS was added into the lower chamber for attracting cells. Subsequently, the cell suspension was cultured in the upper chamber at $37^{\circ} \mathrm{C}$ for $24 \mathrm{~h}$. Cells were stained with $4 \mathrm{~g} / \mathrm{l}$ crystal violet (Tianjin Zhongxin Chemtech, Co., Ltd., Tianjin, China) for $15 \mathrm{~min}$ at room temperature and washed with PBS three times. Finally, cells were observed and images were captured using a light microscope (magnification, x400; Nikon Corporation, Tokyo, Japan). The number of invasive cells was quantified using GraphPad Prism software 6.0 (GraphPad Software, Inc., La Jolla, CA, USA).

Wound healing assay. Cells were inoculated in 6-well plates $\left(2.5 \times 10^{4}\right.$ cells/well) and cultured in an incubator for $24 \mathrm{~h}$. Cells were scratched with a $200-\mu 1$ pipette tip and washed with medium three times. The cells were treated with different concentrations of Zey at 10 (Zey1), 20 (Zey2) and 40 (Zey3) $\mu \mathrm{mol} / 1$. Untreated cells served as a control. The cells were observed and imaged prior to and at 12 and $24 \mathrm{~h}$ post-wound assay under a light microscope (magnification, $\mathrm{x} 400$ ). Wound width was quantified using GraphPad Prism software 6.0.

ELISA. Cells were inoculated in 6-well plates $\left(2.5 \times 10^{4}\right.$ cell $/$ well $)$ and cultured in an incubator for $24 \mathrm{~h}$. Cells were treated with different concentrations of Zey for $48 \mathrm{~h}$ at 10 (Zey1), 20 (Zey2) and 40 (Zey3) $\mu \mathrm{mol} / 1$. Untreated cells served as a control. Subsequently, cells were digested with $0.25 \%$ EDTA-trypsin (Beijing Solarbio Science \& Technology Co., Ltd.) and centrifuged at $800 \mathrm{x}$ g for $5 \mathrm{~min}$ at $4^{\circ} \mathrm{C}$. Following centrifugation, cells were resuspended in F-12K medium. The expression of MMP2/9 was detected using ELISA test kits (cat. nos. MMP200 and DMP900, respectively; R\&D Systems, Inc., Minneapolis, MN, USA). The standard curve was plotted with standard samples. The assay diluent $(50 \mu \mathrm{l})$ was added to each well. In total, $50 \mu \mathrm{l}$ sample in each group was added into each well. The plates was covered with plate sealer and maintained for $2 \mathrm{~h}$ at room temperature. Following washing, the conjugate reagent was added into each well and the plate was placed on a shaker at room temperature for $2 \mathrm{~h}$. The substrate solution was added into each well and maintained for $30 \mathrm{~min}$ at room temperature. Subsequently, the stop solution was used to terminate the reaction. Finally, the absorbance at $450 \mathrm{~nm}$ was read using a FilterMax F3/F5 microplate reader.

Reverse transcription-quantitative polymerase chain reaction $(R T-q P C R)$ assay. TRIzol ${ }^{\circledR}$ reagent (Invitrogen; Thermo Fisher Scientific, Inc., Waltham, MA, USA) was applied to collect total RNA. A total of $1 \mu \mathrm{g}$ RNA was used to synthesize cDNA using an RT Master Mix kit (Takara Biotechnology Co., Ltd., Dalian, China). Reverse transcriptional reaction conditions were set at $85^{\circ} \mathrm{C}$ for $15 \mathrm{~min}$. SYBR Premix Taq ${ }^{\mathrm{TM}}$ II kit (Takara Biotechnology Co., Ltd.) was used to amplify cDNA. The volumes of the amplified reagent were as follows: $25 \mu \mathrm{l}$ SYBR Green Mix; $1 \mu \mathrm{l}$ forward/reverse primers; $4 \mu \mathrm{l}$ cDNA; and nuclease-free $\mathrm{H}_{2} \mathrm{O}$ to a total volume of $50 \mu \mathrm{l}$. The temperature and duration of the amplification were as follows: $92^{\circ} \mathrm{C}$ for $15 \mathrm{~min}$, (at $92^{\circ} \mathrm{C}$ for $20 \mathrm{sec}$ at $65^{\circ} \mathrm{C}$ for $45 \mathrm{sec}$ ) at 35 cycles, at $85^{\circ} \mathrm{C}$ for $20 \mathrm{sec}$, at $37^{\circ} \mathrm{C}$ for $2 \mathrm{~min}$. All primer sequences are listed in Table I. $\beta$-actin was regarded as the internal control. The formula $2^{-\Delta \Delta \mathrm{Cq}}(21)$ was performed to determine the gene expression levels.

Western blotting assay. Cells were lysed with radioimmunoprecipitation assay buffer (Beijing Solarbio Science \& Technology 
Table I. Sequences of the primers.

Primer name

Sequence, 5'-3'

Product size, bp

MMP-2-Forward

MMP-2-Reverse

MMP-9-Forward

MMP-9-Reverse

FN-1-Forward

FN-1-Reverse

TIMP-1-Forward

TIMP-1-Reverse

Collagen-1-Forward

Collagen-1-Reverse

Vimentin-Forward

Vimentin-Reverse

E-cadherin-Forward

E-cadherin-Reverse

$\beta$-actin-Forward

$\beta$-actin-Reverse

CAGCCCTGCAAGTTTCCATT
GTTGCCCAGGAAAGTGAAGG
GAGACTCTACACCCAGGACG
GAAAGTGAAGGGGAAGACGC
TGGCACTGATGAAGAACCCT
GGGAAACTGTGTAGGGGTCA
AGACCACCTTATACCAGCGT
GCCACAAAACTGCAGGTAGT
CATGCCGTGACCTCAAGATG
TCCATCGGTCATGCTCTCTC
AATAAGATCCTGCTGGCCGA
GGTGTTTTCGGCTTCCTCTC
ACGCATTGCCACATACACTC
GGTGTTCACATCATCGTC
GGGAAATCGTGCGTGACATT
AGGTAGTTTCGTGGATGCCA

219

MMP-2, matrix metalloproteinase-2; MMP-9, matrix metalloproteinase-9; FN-1, fibronectin-1; TIMP-1, tissue inhibitor of metalloproteinases-1; E, epithelial.

Co., Ltd.). The content of protein was evaluated by a bicinchoninic protein quantification kit (Yeasen). Protein samples $(25 \mu \mathrm{g}$ per lane) were separated with $10 \%$ SDS-PAGE and subsequently transferred to a polyvinylidene difluoride membrane (EMD Millipore, Billerica, MA, USA). Subsequently, the membrane was blocked with $5 \%$ skimmed milk powder at room temperature for $1.5 \mathrm{~h}$. Following blocking, the membrane was incubated with anti-matrix metalloproteinase (MMP)-2 (R\&D Systems, Inc.; cat. no. IC903G-100UG; 1:1,000), anti-MMP-9 (Abcam, Cambridge, UK; cat. no. EP1254; 1:500), anti-tissue inhibitor of metalloproteinases-1 (TIMP-1; Abcam; cat. no. ab61224; 1:700), anti-vimentin (R\&D Systems, Inc.; cat. no. AF2105; 1:700), anti-epithelial (E)-cadherin (R\&D Systems, Inc.; cat. no. MAB1838; 1:1,000), anti-fibronectin 1 (FN1; Abcam; cat. no. ab32419; 1:800), anti-collagen-1 (Abcam; cat. no. ab90395; 1:600), anti-wnt5a (Abcam; cat. no. ab174963; 1:1,000), anti- $\beta$-catenin (R\&D Systems, Inc.; cat. no. AF1329; 1:1,000), anti-cyclin D1 (R\&D Systems, Inc.; cat. no. MAB4314; 1:900) and anti- $\beta$-actin (Abcam; cat. no. ab13772; 1:800) on the rocking table at $4^{\circ} \mathrm{C}$ for $24 \mathrm{~h}$. The membrane was subsequently incubated in corresponding horseradish peroxidase-conjugated secondary antibodies [rabbit anti-mouse immunoglobulin (Ig)G; Cell Signaling Technology, Inc., Danvers, MA, USA; cat. no. 58802; 1:8,000; mouse anti-rabbit IgG; Cell Signaling Technology, Inc.; cat. no. 5127; 1:7,000; goat anti-mouse IgG; Abcam; cat. no. ab6785; $1: 7,000]$ at $37^{\circ} \mathrm{C}$ for $1 \mathrm{~h}$. The protein was visualized using an enhanced chemiluminescence detection kit (Beyotime Institute of Biotechnology). $\beta$-actin was used as an internal control. Densitometry was conducted using Quantity One software 4.21 (Bio-Rad Laboratories, Inc., Hercules, CA, USA).

Statistical analysis. Data was analyzed using GraphPad Prism software 6.0 (GraphPad Software, Inc., La Jolla, CA, USA).
The data are presented as the mean \pm standard deviation from at least three independent experiments. The differences between groups were assessed by one-way analysis of variance followed by Turkey's text. $\mathrm{P}<0.05$ was considered to indicate a statistically significant difference.

\section{Results}

Zey represses the viability of DU145 cells. A CCK-8 assay was performed to investigate the effect of Zey on the viability of DU145 cells. Cells were treated with Zey at 0, 2.5, 5, 10, 20 and $40 \mu \mathrm{mol} / 1$ for 12,24 and $48 \mathrm{~h}$. The data from the present study demonstrated that cell viability decreased with increasing concentrations of Zey and incubation time. The half maximal inhibitory concentration of Zey was $40 \mu \mathrm{mol} / \mathrm{l}$ at $48 \mathrm{~h}$. The treatment with Zey at 10, 20 and $40 \mu \mathrm{mol} / \mathrm{l}$ for $48 \mathrm{~h}$ caused a significant decrease in the viability of the cells $(\mathrm{P}<0.05$; Fig. 1). Therefore, these concentrations and time were selected as the conditions of the subsequent experiments.

Zey inhibits the invasive ability of DU145 cells. The Matrigel assay was conducted to study the invasive ability of Zey-treated DU145 cells. Cells were treated with Zey at 0 (control), 10 (Zey1), 20 (Zey2) and 40 (Zey3) $\mu \mathrm{mol} / 1$ for $48 \mathrm{~h}$. The results demonstrated that treatment with Zey decreased the number of invading cells in a dose-dependent manner, compared with the control group. The proportion of invasive cells in the Zey1 group was $\sim 67 \%$; whereas, in the Zey2 and Zey3 groups the proportions were $\sim 50$ and $\sim 30 \%$, respectively ( $\mathrm{P}<0.05$; Fig. 2 ).

Zey decreases the migratory ability of DU145 cells. A wound-healing assay was conducted to analyze the effect of Zey on the migratory ability of DU145 cells. Cells were 


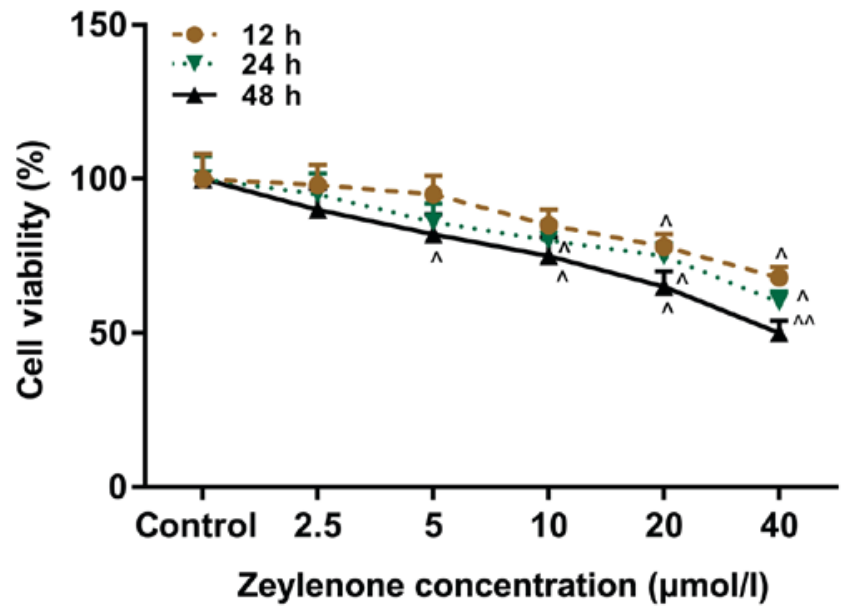

Figure 1. Zey represses the viability of DU145 cells. DU145 cells were administered Zey at $0,2.5,5,10,20$ and $40 \mu \mathrm{mol} / 1$ for 12,24 and $48 \mathrm{~h}$. Cell Counting Kit- 8 was used to investigate the viability of cells. ${ }^{\wedge} \mathrm{P}<0.05,{ }^{\wedge} \mathrm{P}<0.01$ vs. respective control. Zey, Zeylenone.

treated with Zey at 0 (control), 10 (Zey1), 20 (Zey2) and 40 (Zey3) $\mu \mathrm{mol} / 1$ for 0,12 and $24 \mathrm{~h}$. No obvious migration of cells was demonstrated when cells were exposed to $0,10,20$ and $40 \mu \mathrm{mol} / \mathrm{l}$ Zey for $0 \mathrm{~h}$. However, the migratory ability of cells was significantly attenuated when cells were treated with 10 , 20 and $40 \mu \mathrm{mol} / 1$ Zey for 12 and $24 \mathrm{~h}(\mathrm{P}<0.05$; Fig. 3$)$.

Zey regulates ECM-associated factors in DU145 cells. To examine the expression levels of ECM-associated factors, ELISA, RT-qPCR and western blotting assays were performed. Cells were treated with Zey at 0 (control), 10 (Zey1), 20 (Zey2) and 40 (Zey3) $\mu \mathrm{mol} / 1$ for $48 \mathrm{~h}$. The ELISA data identified that Zey significantly decreased the expression levels of MMP-2 and MMP-9 in a concentration-dependent manner $(\mathrm{P}<0.05$; Fig. 4A). In addition, the results of RT-qPCR demonstrated that when cells were exposed to Zey $(10,20$ and $40 \mu \mathrm{mol} / \mathrm{l})$, the mRNA expression levels of MMP-2, MMP-9 and FN-1 significantly decreased, whereas, the expression levels of TIMP-1 and collagen-1 significantly increased $(\mathrm{P}<0.05$; Fig. 4B). As demonstrated by the western blotting assays, the protein expressions were similar to that of mRNA ( $\mathrm{P}<0.05$; Fig. 4C).

Zey regulates EMT-associated factors in DU145 cells. To investigate the expression levels of EMT-associated factors, RT-qPCR and western blot assays were performed. Cells were treated with Zey at 0 (control), 10 (Zey1), 20 (Zey2) and 40 (Zey3) $\mu \mathrm{mol} / 1$ for $48 \mathrm{~h}$. The RT-qPCR results demonstrated that Zey significantly decreased the mRNA expression level of vimentin; however, increased the E-cadherin mRNA expression level in a dose-dependent manner $(\mathrm{P}<0.05 ;$ Fig. $5 \mathrm{~A})$. In addition, the western blotting data revealed that the protein expression of vimentin was significantly downregulated; whereas, the protein expression level of E-cadherin was upregulated in Zey-treated cells ( $\mathrm{P}<0.05$; Fig. 5).

Zey suppresses the Wnt/ $\beta$-catenin signaling pathway in DU145 cells. To further analyze whether Zey suppressed growth and metastasis by regulating the $\mathrm{Wnt} / \beta$-catenin pathway, a western blotting assay was used to determine the protein expression levels of wnt5a, $\beta$-catenin and cyclin D1. Cells were subjected to Zey at 0 (control), 10 (Zey1), 20 (Zey2) and 40 (Zey3) $\mu \mathrm{mol} / 1$ for $48 \mathrm{~h}$. The data demonstrated that the expressions of wnt5a, $\beta$-catenin and cyclin D1 were significantly decreased in cells treated with Zey $(\mathrm{P}<0.05$; Fig. 6).

\section{Discussion}

$\mathrm{PCa}$ is one of the most common tumors of the urinary system in men. The continuous metastasis and proliferation of $\mathrm{PCa}$ cells are important clinical features and a principal cause of mortality in the advanced stage of this cancer $(22,23)$. It was demonstrated that Zey demonstrates cytotoxicity to tumor cells $(10,24)$. Similar to previous studies $(8,9)$, the present study demonstrated that Zey decreased the viability of DU145 cells. Previous studies demonstrated that Zey markedly suppresses growth and promotes apoptosis in cervical tumor cells $(8,9)$. However, to the best of our knowledge, no study has investigated the role of Zey in PCa. In the present study, the effect of Zey on the metastasis of DU145 cells was analyzed. The results revealed that Zey suppressed the invasive and migratory capabilities of DU145 cells.

Subsequently, the molecular mechanism of Zey inhibiting the proliferation and metastasis of $\mathrm{PCa}$ was further examined. It is widely accepted that the ECM may regulate the rate and direction of cell metastasis and provide 'scaffolding' for cell metastasis. By affecting the balance of ECM degradation, MMPs achieve a pathological and physiological significance (14). In addition, FN and collagen are the primary components of the ECM. Their deregulated expression will result in increased invasiveness of breast cancer cells (25). Furthermore, TIMP inhibits basement membrane degradation, endothelial cell formation and angiogenesis by depressing the function of MMPs, and in this way, TIMP affects the invasion and migration progress of a tumor (26). The results of the present study demonstrated that Zey decreased the expression levels of MMP-2, MMP-9 and FN1, and promoted TIMP-1 and collagen-1 expression. Therefore, the present study demonstrated that ECM components contributed to Zey-inhibited metastasis in PCa cells.

Furthermore, EMT is dysregulated in various tumors, which affects tumor proliferation and metastasis. E-cadherin maintains intercellular connections through intracellular and extracellular adhesion (27). Therefore, reducing the expression of E-cadherin will induce metastasis of cancer cells (28). Additionally, vimentin is another key factor during the progression of EMT. The increased expression of vimentin attenuates the cell adhesion function, resulting in the occurrence of tumor metastasis (29). Similar results were observed in the present study; it was demonstrated that the expression level of vimentin was downregulated; however, the E-cadherin expression level was upregulated in DU145 cells exposed to Zey, suggesting that EMT is additionally involved in Zey-inhibited metastasis in PCa cells.

Previous studies demonstrated that the Wnt/ $\beta$-catenin signaling pathway is the key signal transduction pathway that induces EMT in tumor cells (30-32). A previous study suggested that Jatrophone depresses the proliferation and metastasis of breast cancer via the inhibition of the Wnt/ $\beta$-catenin signaling pathway and EMT (30). The regulation of the $\mathrm{Wnt} / \beta$-catenin signaling pathway is caused by the phosphorylation/degradation 
A

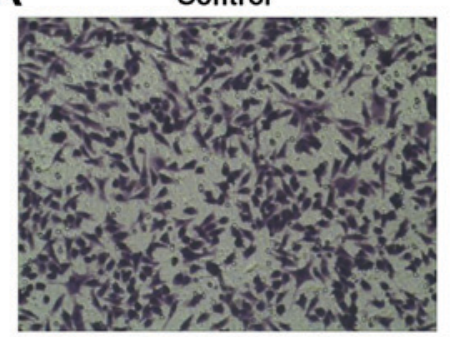

Zey3

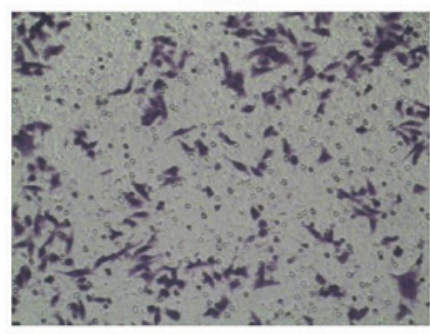

Zey1

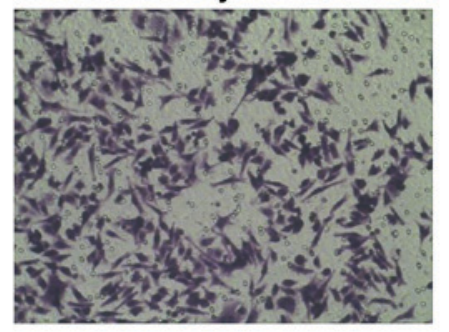

B

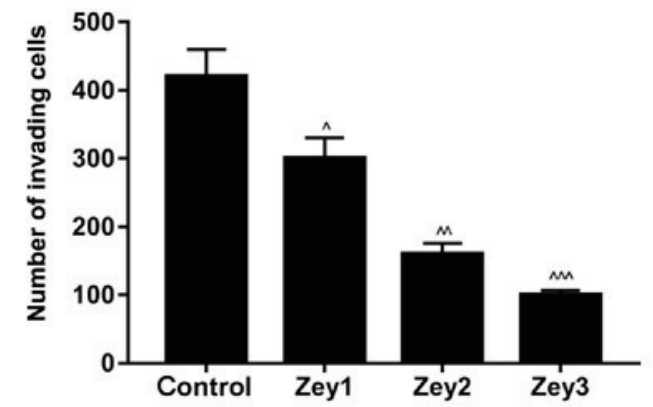

Figure 2. Zey inhibits the invasion ability of DU145 cells. (A) DU145 cells were subjected to Zey at 0 (control), 10 (Zey1), 20 (Zey2) and 40 (Zey3) $\mu$ mol/1 for $48 \mathrm{~h}$. A transwell assay was performed to evaluate the invasive capacity of cells (magnification, $\mathrm{x} 400$ ). (B) Number of invasive cells was quantified using GraphPad Prism software. ${ }^{\wedge} \mathrm{P}<0.05,{ }^{\wedge} \mathrm{P}<0.01,{ }^{\wedge \wedge} \mathrm{P}<0.001$ vs. control. Zey, Zeylenone.

A

A

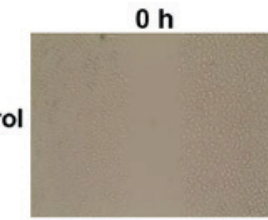

Zey1
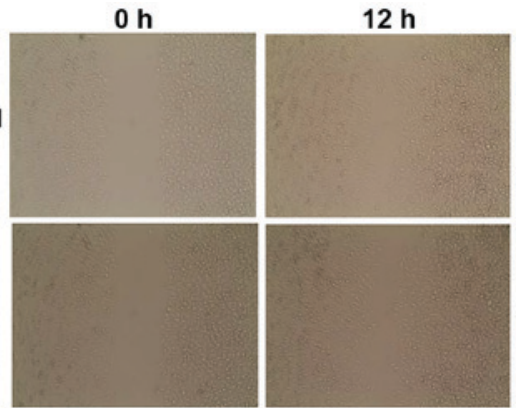

Zey2
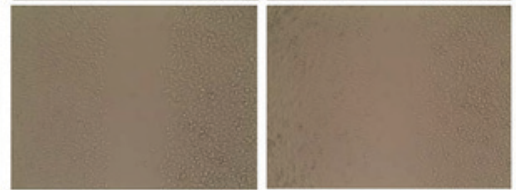

Zey3
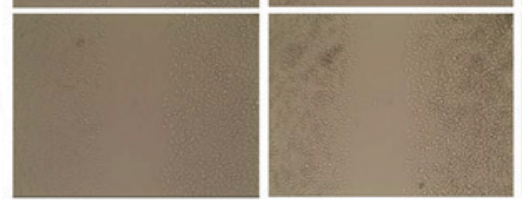

B

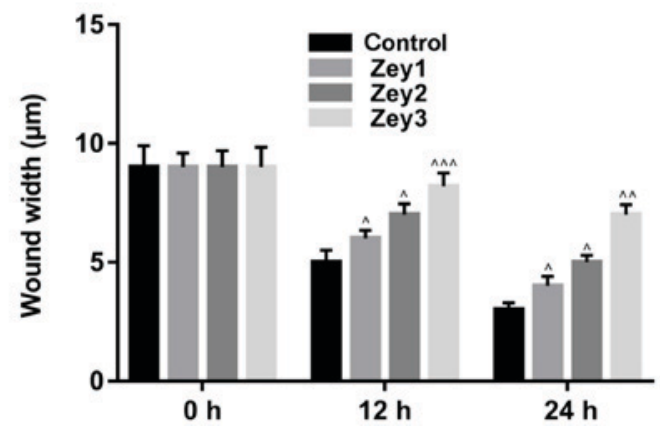

Figure 3. Zey decreases the migratory ability of DU145 cells. (A) DU145 cells were treated with Zey at 0 (control), 10 (Zey1), 20 (Zey2) and 40 (Zey3) $\mu \mathrm{mol} / 1$ for 0,12 and $24 \mathrm{~h}$. A wound-healing assay was used to determine the migratory capacity of cells (magnification, $\mathrm{x} 400$ ). (B) Wound width was quantified using GraphPad Prism software. ${ }^{\wedge} \mathrm{P}<0.05,{ }^{\wedge} \mathrm{P}<0.01,{ }^{\wedge \wedge} \mathrm{P}<0.001$ vs. respective control. Zey, Zeylenone. of $\beta$-catenin (33). Wnt5a, one of the members of the Wnt protein family, may induce melanoma EMT and metastasis through the protein kinase $\mathrm{C}$ signaling pathway (34). Therefore, it was hypothesized that the molecular mechanisms of Zey on PCa growth and metastasis were pertinent to the Wnt/ $\beta$-catenin pathway. Consistent with the mentioned previous studies, the results of the present study demonstrated that Zey decreased the expression levels of Wnt5a, $\beta$-catenin and cyclin D1 in DU145 cells, suggesting that Zey attenuated the activity of the Wnt/ $\beta$-catenin signaling pathway.

A limitation of the present study was that the effects of Zey were only determined in one cell line of $\mathrm{PCa}$, and therefore future studies should investigate the role of Zey in numerous PCa cell lines. In addition, future studies should investigate the effect of Zey in vivo, which may elucidate a candidate therapeutic agent for the prevention of PCa.

In conclusion, the present study demonstrated that Zey repressed the viability, invasion and migration of PCa DU145 cells in a dose-dependent manner. The suppression of the Wnt/ $\beta$-catenin pathway was closely associated with the effect of Zey. Therefore, Zey may be a novel therapeutic strategy for the treatment of PCa.

\section{Acknowledgements}

Not applicable.

\section{Funding}

No funding was received.

\section{Availability of data and materials}

The analysed data sets generated during the present study are available from the corresponding author on reasonable request. 

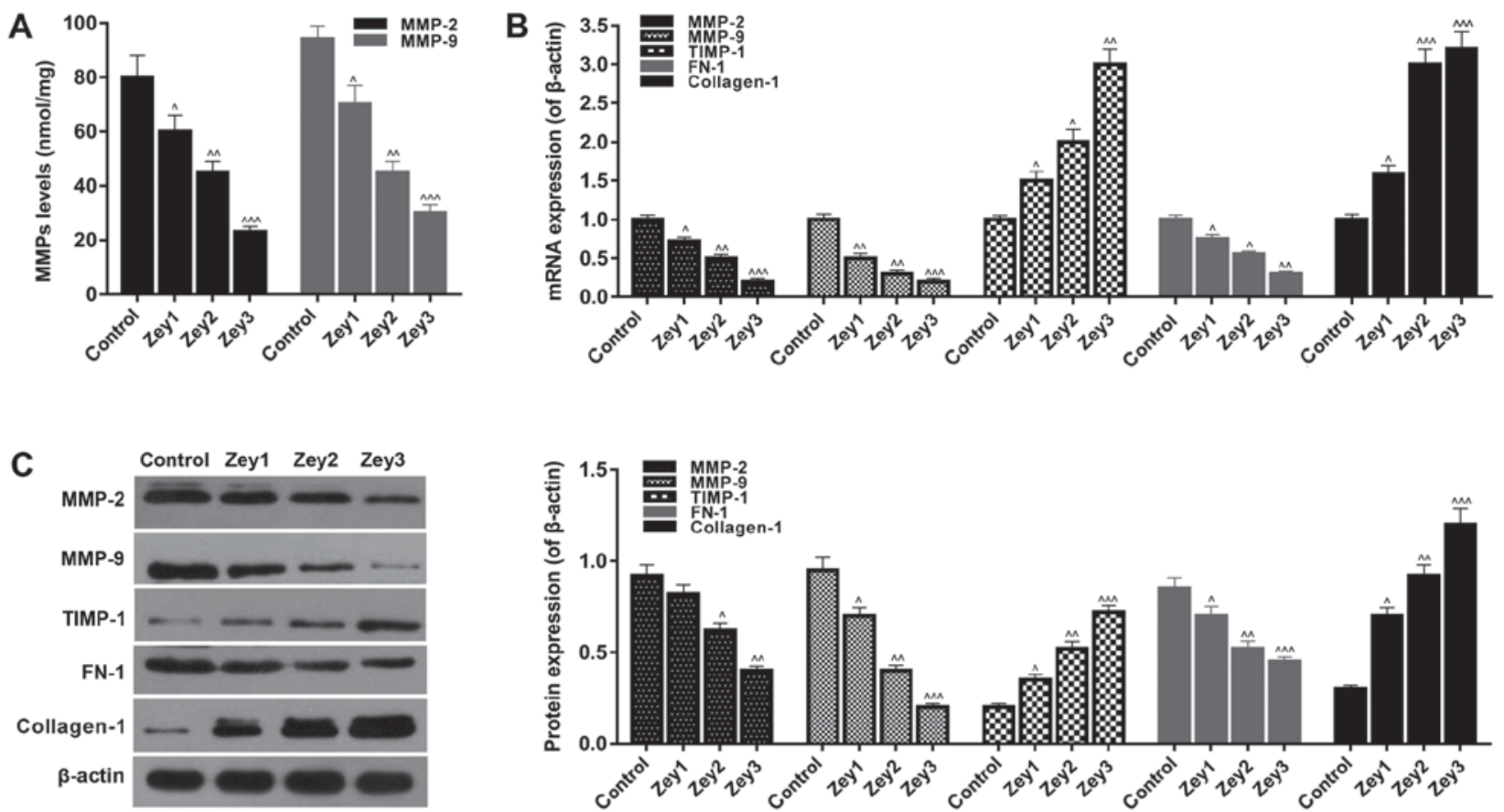

Figure 4. Zey regulates extracellular matrix-associated factors in DU145 cells. (A) DU145 cells exposed to Zey at 0 (control), 10 (Zey1), 20 (Zey2) and 40 (Zey3) $\mu \mathrm{mol} / 1$ for $48 \mathrm{~h}$. Expression levels of MMP-2 and MMP-9 were detected using an ELISA. (B) mRNA expressions of MMP-2, MMP-9, TIMP-1, FN-1 and collagen-1 were measured by a reverse transcription-quantitative polymerase chain reaction assay. (C) Protein expression of MMP-2, MMP-9, TIMP-1, FN-1 and collagen-1 were measured by western blot analysis and normalized to $\beta$-actin expression. Gray value was evaluated and quantified using Quantity One software. ${ }^{\wedge} \mathrm{P}<0.05,{ }^{\wedge} \mathrm{P}<0.01,{ }^{\wedge \wedge} \mathrm{P}<0.001$ vs. respective control. Zey, Zeylenone; MMP, matrix metalloproteinase; TIMP, tissue inhibitor of metalloproteinases; FN-1, fibronectin.
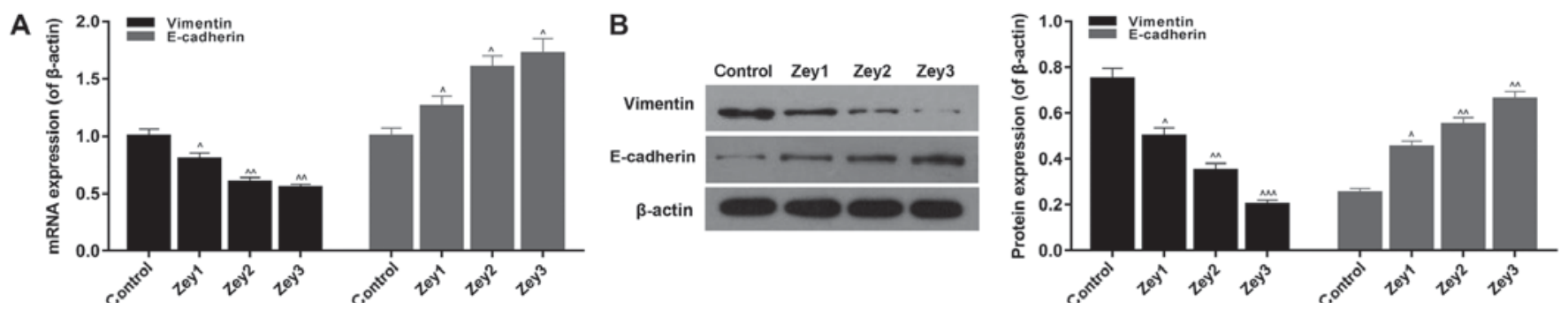

Figure 5. Zey regulates epithelial-mesenchymal transition-associated factors in DU145 cells. (A) DU145 cells were administered with Zey at 0 (control), 10 (Zey1), 20 (Zey2) and 40 (Zey3) $\mu \mathrm{mol} / 1$ for $48 \mathrm{~h}$. Reverse transcription-quantitative polymerase chain reaction was conducted to assess the mRNA expression of vimentin and E-cadherin. (B) Western blot analysis was used to determine the protein expression of vimentin and E-cadherin. $\beta$-actin was presented as the internal control. Gray value was assessed and calculated using Quantity One software. ${ }^{\wedge} \mathrm{P}<0.05,{ }^{\wedge} \mathrm{P}<0.01,{ }^{\wedge \wedge} \mathrm{P}<0.001$ vs. respective control. Zey, Zeylenone; E, epithelial.

A

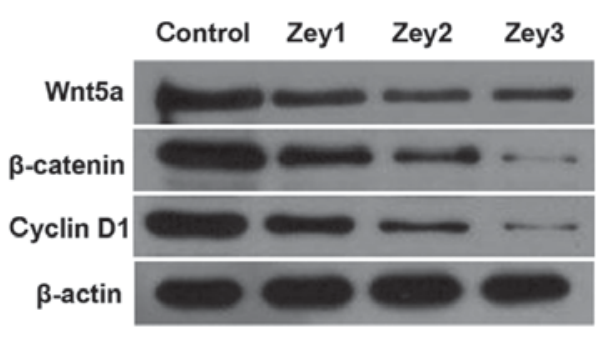

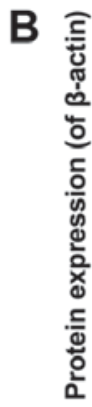

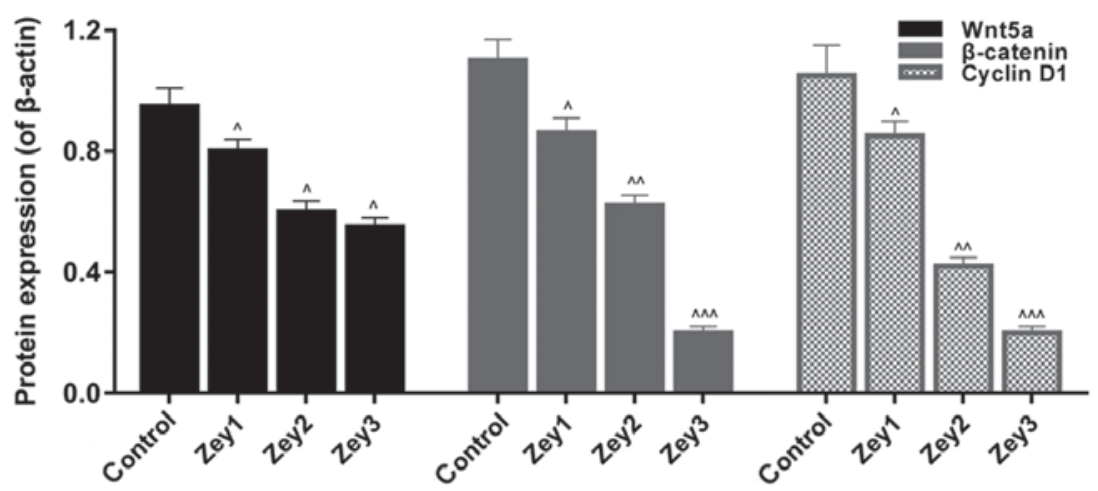

Figure 6. Zey suppresses the Wnt/\$-catenin pathway in DU145 cells. (A) DU145 cells were administrated with Zey at 0 (control), 10 (Zey1), 20 (Zey2) and 40 (Zey3) $\mu \mathrm{mol} / 1$ for $48 \mathrm{~h}$. Western blot analysis was performed to measure the protein expression of wnt5a, $\beta$-catenin and cyclin D1. (B) Quantification of protein was executed using GraphPad Prism software. $\beta$-actin was regarded as the internal control. Gray value was assessed and calculated using Quantity One software. ${ }^{\wedge} \mathrm{P}<0.05,{ }^{\wedge} \mathrm{P}<0.01,{ }^{\wedge \wedge} \mathrm{P}<0.001$ vs. respective control. Zey, Zeylenone. 


\section{Authors' contributions}

SZ wrote the manuscript. SZ, BZ, JZ and WW performed the experiments. SZ and CJ designed the study. SZ, BZ, JZ and WW performed the data analysis. SZ and CJ revised the manuscript. All authors reviewed the manuscript.

\section{Ethics approval and consent to participate}

Not applicable.

\section{Patient consent for publication}

Not applicable.

\section{Competing interests}

The authors declare they have no competing interests.

\section{References}

1. Siegel R, Naishadham D and Jemal A: Cancer statistics, 2012. CA Cancer J Clin 62: 10-29, 2012.

2. Pang C, Guan Y, Li H, Chen W and Zhu G: Urologic cancer in China. Jpn J Clin Oncol 46: 497-501, 2016.

3. Zhu Y, Yang XQ, Han CT, Dai B, Zhang HL, Shi GH, Wang CF and Ye DW: Pathological features of localized prostate cancer in China: A contemporary analysis of radical prostatectomy specimens. PLoS One 10: e0121076, 2015.

4. Acosta AM, Al Rasheed MRH, Rauscher GH, Vormittag E, Mon KS, Sharif A, Kajdacsy-Balla A and Mohapatra G: Tumor necrosis in radical prostatectomies with high-grade prostate cancer is associated with multiple poor prognostic features and a high prevalence of residual disease. Hum Pathol 75: 1-9, 2018.

5. Wang C, Tao W, Ni S, Chen Q, Zhao Z, Ma L, Fu Y and Jiao Z: Tumor-suppressive microRNA-145 induces growth arrest by targeting SENP1 in human prostate cancer cells. Cancer Sci 106 375-382, 2015 .

6. Ding C, Tian Q, Li J, Jiao M, Song S, Wang Y, Miao Z and Zhang A: Structural modification of natural product Tanshinone I leading to discovery of novel nitrogen-enriched derivatives with enhanced anticancer profile and improved drug-like properties. J Med Chem 61: 760-776, 2018.

7. Han C, Li Z, Hou J, Wang Z, Xu D, Xue G and Kong L: Bioactivity evaluation of natural product $\alpha$-mangostin as a novel xanthone-based lysine-specific demethylase 1 inhibitor to against tumor metastasis. Bioorg Chem 76: 415-419, 2018.

8. Zhang L, Huo X, Liao Y, Yang F, Gao L and Cao L: Zeylenone, a naturally occurring cyclohexene oxide, inhibits proliferation and induces apoptosis in cervical carcinoma cells via PI3K/AKT/mTOR and MAPK/ERK pathways. Sci Rep 7: 1669, 2017.

9. Zhang L, Jin J, Zhang L, Hu R, Gao L, Huo X, Liu D, Ma X, Wang C, Han J, et al: Quantitative analysis of differential protein expression in cervical carcinoma cells after zeylenone treatment by stable isotope labeling with amino acids in cell culture. J Proteomics 126: 279-287, 2015.

10. Hu X, Han R, Quan LH, Liu CY and Liao YH: Stabilization and sustained release of zeylenone, a soft cytotoxic drug, within polymeric micelles for local antitumor drug delivery. Int $\mathbf{J}$ Pharm 450: 331-337, 2013.

11. Zhang LL, Li RY, Zhang LJ, Chen D, Huo XW, Li LY and Cao L: Inhibitory effect of Zeylenone on proliferation and apoptosis of human PC-3 cells. Chine Pharmacol Bull 29: 809-813, 2013.

12. Airola K, Karonen T, Vaalamo M, Lehti K, Lohi J, Kariniemi AL, Keski-Oja J and Saarialho-Kere UK: Expression of collagenases-1 and -3 and their inhibitors TIMP-1 and -3 correlates with the level of invasion in malignant melanomas. Br J Cancer 80: 733-743, 1999.

13. Barriere G, Tartary M and Rigaud M: Metformin: A rising star to fight the epithelial mesenchymal transition in oncology. Anticancer Agents Med Chem 13: 333-340, 2013.

14. Elkin M, Ariel I, Miao HQ, Nagler A, Pines M, de-Groot N, Hochberg A and Vlodavsky I: Inhibition of bladder carcinoma angiogenesis, stromal support, and tumor growth by halofuginone. Cancer Res 59: 4111-4118, 1999.
15. Kahlert UD, Nikkhah G and Maciaczyk J: Epithelial-tomesenchymal(-like) transition as a relevant molecular event in malignant gliomas. Cancer Lett 331: 131-138, 2013.

16. Gillers BS, Chiplunkar A,Aly H, Valenta T, BaslerK, Christoffels VM, Efimov IR, Boukens BJ and Rentschler S: Canonical wnt signaling regulates atrioventricular junction programming and electrophysiological properties. Cir Res 116: 398-406, 2015.

17. Monga SP: $\beta$-catenin signaling and roles in liver homeostasis, injury, and tumorigenesis. Gastroenterology 148: 1294-1310, 2015.

18. Li J, Yang S, Su N, Wang Y, Yu J, Qiu H and He X: Overexpression of long non-coding RNA HOTAIR leads to chemoresistance by activating the Wnt $/ \beta$-catenin pathway in human ovarian cancer. Tumour Biol 37: 2057-2065, 2016.

19. Peng Y,Zhang X, Ma Q, Yan R, Qin Y, Zhao Y, Cheng Y, Yang M, Wang Q, Feng X, et al: MiRNA-194 activates the Wnt/ $\beta$-catenin signaling pathway in gastric cancer by targeting the negative Wnt regulator, SUFU. Cancer Lett 385: 117-127, 2017.

20. Vilchez V, Turcios L, Marti F and Gedaly R: Targeting Wnt/ $\beta$-catenin pathway in hepatocellular carcinoma treatment. World J Gastroenterol 22: 823-832, 2016.

21. Livak KJ and Schmittgen TD: Analysis of relative gene expression data using real-time quantitative PCR and the 2(-Delta Delta C(T)) method. Method 25: 402-408, 2001.

22. Huang K, Tang Y, He L and Dai Y: MicroRNA-340 inhibits prostate cancer cell proliferation and metastasis by targeting the MDM2-p53 pathway. Oncol Rep 35: 887-895, 2016.

23. Li Y, Luo H, Xiao N, Duan J, Wang Z and Wang S: Long noncoding RNA SChLAP1 accelerates the proliferation and metastasis of prostate cancer via targeting miR-198 and promoting the MAPK1 pathway. Oncol Res 26: 131-143, 2018.

24. Wei XL, Han R, Hu X, Quan LH, Liu CY, Chang Q and Liao YH: Stabilization of zeylenone in rat plasma by the presence of esterase inhibitors and its LC-MS/MS assay for pharmacokinetic study. Biomed Chromatogr 27: 636-640, 2013.

25. Wang K, Wu F, Seo BR, Fischbach C, Chen W, Hsu L and Gourdon D: Breast cancer cells alter the dynamics of stromal fibronectin-collagen interactions. Matrix Biol 60-61: 86-95, 2017.

26. Zhou XM, Hou G, Gu DX, Wang QY and Zhao L: Peroxisome proliferator-activated receptor- $\gamma$ in induced sputum is correlated with MMP-9/TIMP-1 imbalance and formation of emphysema in COPD patients. J Thorac Dis 9: 3703-3710, 2017.

27. Hatmaker AR, Gi YJ, Schmidt CR, Beauchamp RD, Coffey RJ and Pearson AS: Targeted loss of E-cadherin is sufficient to induce dedifferentiation, loss of intercellular junctions, and increased invasive potential of colorectal cancer cells. Cancer Res 66: 588, 2006.

28. Vu T and Datta PK: Regulation of EMT in colorectal cancer: A culprit in metastasis. Cancers (Basel) 9: pii: E171, 2017.

29. Chouat E, Zehani A, Chelly I, Njima M, Maghrebi H, Bani MA, Njim L, Zakhama A, Haouet S and Kchir N: Tumor budding is a prognostic factor linked to epithelial mesenchymal transition in pancreatic ductal adenocarcinoma. Study report and literature review. Pancreatology 18: 79-84, 2018.

30. Fatima I, El-Ayachi I, Taotao L, Lillo MA, Krutilina R, Seagroves TN, Radaszkiewicz TW, Hutnan M, Bryja V, Krum SA, et al: The natural compound Jatrophone interferes with Wnt/ß-catenin signaling and inhibits proliferation and EMT in human triple-negative breast cancer. PLoS One 12: e0189864, 2017.

31. Jiang Y, Ren W, Wang W, Xia J, Gou L, Liu M, Wan Q, Zhou L, Weng Y, He T and Zhang Y: Inhibitor of $\beta$-catenin and TCF (ICAT) promotes cervical cancer growth and metastasis by disrupting E-cadherin/ $\beta$-catenin complex. Oncol Rep 38: 2597-2606, 2017.

32. Xie SL, Fan S, Zhang SY, Chen WX, Li QX, Pan GK, Zhang HQ, Wang WW, Weng B, Zhang Z, et al: SOX8 regulates cancer stem-like properties and cisplatin-induced EMT in tongue squamous cell carcinoma by acting on the $\mathrm{Wnt} / \beta$-catenin pathway. Int J Cancer 142: 1252-1265, 2018.

33. Clevers $\mathrm{H}$ and Nusse R: Wnt/ $\beta$-catenin signaling and disease. Cell 149: 1192-1205, 2012.

34. Dissanayake SK, Wade M, Johnson CE, O'Connell MP, Leotlela PD, French AD, Shah KV, Hewitt KJ, Rosenthal DT, Indig FE, et al: The Wnt5A/protein kinase C pathway mediates motility in melanoma cells via the inhibition of metastasis suppressors and initiation of an epithelial to mesenchymal transition. J Biol Chem 282: 17259-17271, 2007.

This work is licensed under a Creative Commons Attribution-NonCommercial-NoDerivatives 4.0 International (CC BY-NC-ND 4.0) License. 